\title{
PHENYLALANINE METABOLISM IN THE PHENYLPYRUVIC CONDITION. I. DISTRIBUTION, POOL SIZE, AND TURNOVER RATE IN HUMAN PHENYLKETONURIA *
}

\author{
By HANNS-DIETER GRÜMER, HANS KOBLET AND CAROL WOODARD
}

(From the Biochemical Laboratory, Pineland Hospital and Training Center, Pownal, Maine; and the Arthur G. Rotch Research Laboratories, The Boston Dispensary, Boston, Mass.)

(Submitted for publication March 25, 1960 ; accepted May 19, 1961)

The inborn metabolic error in phenylpyruvic oligophrenia consists of the inability to hydroxylate phenylalanine to tryrosine in any significant amount. Recent work has focused mainly on the investigation of this hydroxylating system, its purification and mode of action (1-5), the inhibitory effect of phenylalanine and its derivatives on enzymes (6-9), and the prevention of mental retardation by a diet low in phenylalanine $(10,11)$.

With this diet the free phenylalanine of plasma and total body fluid can be adjusted to any value that might be required to study the effect of phenylalanine concentration on metabolic processes in vivo. Bickis, Kennedy and Quastel (12), for example, demonstrated that phenylalanine, at concentrations similar to those observed in the blood of phenylketonuric patients, inhibited the enzymatic degradation of tyrosine in vitro. We, on the other hand (13), were unable to find inhibition of the breakdown of orally administered $p$-hydroxyphenylpyruvic acid in patients with plasma concentrations of phenylalanine as high as $50 \mathrm{mg}$ per $100 \mathrm{ml}$. This discrepancy could be explained, for instance, by a diminished rate of $p$-hydroxyphenylpyruvic acid formation from tyrosine in the in vitro experiments, or by a lower intracellular phenylalanine concentration in our in vivo study than one would have expected from the plasma phenylalanine levels. Since the distribution coefficient of phenylalanine between tissue and plasma has not yet been determined in vivo, the intracellular phenylalanine concentrations in our experiments were not known. In order to evaluate properly the significance of metabolic experiments with phenylalanine, some estimate must be made of the distribution of the phenylalanine between plasma and tissue.

Since patients with phenylpyruvic oligophrenia

* This work was supported by Research Grants 2729 and 3961 from the National Institute of Mental Health. demonstrate a defined metabolic variation from the norm, they also provide the opportunity to obtain further information that is not readily available in normal subjects. For example, pool size determinations of amino acids have rarely been performed and have mostly proved to be unsatisfactory, bceause they are based on experiments with $\mathrm{N}^{15}$-labeled amino acids and many assumptions have to be made [see $\mathrm{Wu}$, Sendroy and Bishop $(14,15)$ and Tschudy and co-workers (16)]. Experiments similar to ours with $\mathrm{S}^{35}$ labeled methionine in nonphenylketonuric individuals have been published by Maurer (17). To our knowledge no studies on human beings have been made, so far, with $\mathrm{C}^{14}$-labeled amino acids, except by Gutman and co-workers (18), who estimated the pool size of glycine. The method used by them, however, was entirely different from ours.

The use of $\mathrm{C}^{14}$-labeled amino acids eliminates the necessity of assuming, as did Sprinson, Rittenberg and San Pietro $(19,20)$, that the rate of nitrogen transfer is faster than other metabolic processes involved here. It will be shown later that we have to make a similar assumption; namely, that equilibration of the labeled phenylalanine within the body is faster than other processes. If it be assumed that the conversion of phenylalanine to tyrosine is negligible in the penylketonuric patient, then phenylalanine can only be stored, incorporated into proteins, excreted as such or as its metabolites-phenylpyruvic acid and phenylacetic acid.

That this assumption is correct will be shown in a second paper (21). In addition, no appreciable amount of phenylpyruvic acid or phenylacetic acid has been found in the circulating plasma of phenylpyruvic patients in comparison with the total amount of free phenylalanine (22). Therefore, the pool size, the turnover time, and the absolute turnover rate of free phenylalanine pool 
can be estimated by means of $\mathrm{C}^{14}$-labeled phenylalanine without isolating free phenylalanine from the plasma. The absolute turnover rate in the phenylketonuric organism is, therefore, only the sum of incorporation into proteins, excretion, and conversion to compounds other than tyrosine. However, a small, nonspecific conversion to tyrosine might be included. In respect to many metabolic functions, phenylketonuric patients seem to behave like normal individuals; but from a metabolic point of view they may be considered human mutants. Thus, it might be possible to carry out studies at normal phenylalanine levels, taking advantage of the existence of the metabolic block, to derive data applicable to persons other than phenylketonurics.

\section{MATERIALS AND METIIODS}

Two male and two female patients suffering from phenylpyruvic oligophrenia were studied. Three (J.I., N.C. and K.H.) had been on a diet low in phenylalanine for at least 3 weeks prior to the experiments. High protein foods were replaced by a casein hydrolysate from which phenylalanine had been removed (Lofenalac, Mead Johnson Co.). The plasma phenylalanine was adjusted to levels of $2.3 \mathrm{mg}$ in J.I., $7.0 \mathrm{mg}$ in N.C., and 10.5 and $17.0 \mathrm{mg}$ per $100 \mathrm{ml}$ in K.H.1 and K.H.. (the experiments in K.H. were carried out on two different occasions). No phenylpyruvic acid was excreted in the urine as checked by the ferric chloride test. Patient R.S. was maintained on a normal diet, excreted large amounts of phenylpyruvic acid, and had a plasma phenylalanine concentration of $47 \mathrm{mg}$ per $100 \mathrm{ml}$ plasma. The experiments were carried out on 3 consecutive days, in the morning. Breakfast was omitted.

First day. Determination of antipyrine space was done according to Brodie, Axelrod, Soberman and Levy (23).

Second day. A needle with a three-way stopcock was inserted into the cubital vein and a blood sample was taken for the determination of the free phenylalanine plasma level, total plasma proteins, hematocrit, and hemoglobin. About $8 \times 10^{6} \mathrm{cpm}$ to $11 \times 10^{8} \mathrm{cpm}$ of uniformly labeled L-phenylalanine- $\mathrm{C}^{14}{ }^{1}$ (specific activity $3.2 \times 10^{7}$ cpm per $\mathrm{mg}$ ), dissolved in $30 \mathrm{ml}$ of physiological saline, was injected through the needle and the syringe was washed three times with about $10 \mathrm{ml}$ of saline from an attached infusion bottle. A constant saline infusion was started for 5 to 6 hours (the duration of the experiments), the total amounting to not more than $350 \mathrm{ml}$.

Heparinized blood samples were taken at short intervals for 5.5 hours; in Patient K.H.1 for 48 hours. The

\footnotetext{
${ }_{1}^{1}$ Nuclear Chicago. This corporation claims that their L-phenylalanine- $\mathrm{C}^{\mathbf{1 4}}$ has a radiochemical purity of 100 per cent, and a chromotographic and electrophoretic purity of about 99 per cent.
}

heparinized blood samples were centrifuged at $700 \mathrm{RCF}$ for 10 minutes. In order to determine the radioactivity of the free $\mathrm{L}$-phenylalanine in deproteinized plasma, 1.0 $\mathrm{ml}$ of plasma was added to $2.0 \mathrm{ml}$ of $10 \mathrm{~g}$ per $100 \mathrm{ml}$ of an aqueous solution of trichloroacetic acid (TCA).

The resulting precipitate was centrifuged at 1,400 RCF for 20 minutes and a duplicate $1.0 \mathrm{ml}$ of the supernatant was plated on plastic planchets, $7.1 \mathrm{~cm}^{2}$ in area, and dried at room temperature for counting. The samples were counted in a gas-flow end-window counter with a Micromil window and an efficiency of about 22 per cent. All values were corrected for background and self-absorption and given in counts per minute for $1.0 \mathrm{ml}$ of plasma.

The latter values were plotted on semilogarithmic paper against time, and the resulting first straight line was extrapolated to zero time $\left(t_{0}\right)$. This zero time value was used to calculate the distribution volume by the formula:

$$
\frac{\mathrm{cpm} \text { injected }}{\mathrm{cpm} \text { per } 1.0 \mathrm{ml} \text { protein-free plasma at } t_{0}}
$$

The pool size of the free phenylalanine is the product of the distribution volume and the free phenylalanine plasma concentration in milliliters.

The slope of the first straight line, so obtained, permitted the estimation of the half-life time and the turnover time of the pool. The turnover time, as used here, is the reciprocal of the slope constant. The absolute turnover rate is given by the quotient of milligrams of free phenylalanine pool to turnover time in minutes. The average concentration in $1.0 \mathrm{ml}$ extravascular antipyrine space was derived from the following equation by Dost (24):

$$
a_{\text {tissue }}=\frac{\text { amount injected }-a_{\text {plasma }} \times V_{\text {plasma }}}{V_{\text {antip. }}-V_{\text {plasma }}}
$$

where $a_{\mathrm{tissue}}=$ average apparent phenylalanine concentration in $\mathrm{cpm} \times \mathrm{ml}^{-1}$ extravascular antipyrine space at $t_{0}$; $a_{\text {plasma }}=$ apparent phenylalanine level in $\mathrm{cpm} \times \mathrm{ml}^{-1}$ plasma at $t_{0} ; V_{\text {plasma }}=$ Evans blue space in $\mathrm{ml} ; V_{\text {antip. }}$. $=$ antipyrine space in $\mathrm{ml}$; and the distribution quotient is given by:

$$
\frac{a_{\text {tissue }}}{a_{\text {plasma }}}
$$

Third day. Plasma volume determinations were carried out by injecting $5.0 \mathrm{ml}$ of 0.5 per cent aqueous solution of Evans blue (Warner-Chilcott).

Blood samples were taken at 10, 20, and 30 minutes, as well as before injecting the dye. The heparinized blood was centrifuged at $700 \mathrm{RCF}$ and the clear, nonhemolyzed supernatant was measured at $600 \mathrm{~m} \mu$ in the Beckman DU spectrophotometer. The resulting optical densities were plotted on linear graph paper and extrapolated to zero time. From the value so obtained the dilution of the dye was calculated.

In Patient N.C. the plasma volume was estimated to be $1 / 22$ of the body weight. Determination of free phenylalanine was carried out by means of an enzymatic method by La Du and Michael (25) ; total plasma protein was determined with the biuret technique (26). 


\section{RESULTS AND DISCUSSION}

The first part of the disappearance curve reflects the equilibration of the labeled phenylalanine among blood, extracellular space, and intracellular space of a multitude of compartments, as well as the turnover of the labeled phenylalanine. The term "turnover" as used here refers to all metabolic processes, including incorporation into proteins and excretion, but excluding the initial equilibration. A first equilibrium of the isotope is reached in J.I., N.C., K.H.1 , and K.H.. 20 and 30 minutes, and in Patient R.S., with the high phenylalanine level of $47 \mathrm{mg}$ per $100 \mathrm{ml}$ plasma, at about 90 minutes (Figure 1); from there a straight line was obtained for some time during the course of the experiment. If we assume that at the beginning of this first straight line (the second part of the disappearance curve) the equilibration processes have essentially come to an end, then the turnover of the labeled amino acid can be estimated solely from the first straight line. ${ }^{2}$ This assumption finds some support in comparing the antipyrine space and the phenylalanine space as derived from the extrapolation of the first straight line to zero time; both spaces are of the same order of magnitude. The quotient of phenylalanine space to antipyrine space varied from 0.80 to 1.53 with an average of 1.04. This indicates that probably no essential enrichment of phenylalanine, if any, above plasma phenylalanine levels has taken place. However, it should be emphasized that the values for the phenylalanine space and the phenylalanine pool are only approximations. This applies especially to Patients J.I. and N.C. in whom the relatively rapid turnover and the large space of distribution, which requires significant time for equilibration of the radioactive phenylalanine (about 20 minutes), mean that the processes of mixing and turnover may proceed simultaneously at comparable rates. Since turnover probably occurs only, or primarily, within cells, there is little turnover of labeled phenylalanine going on during the very first part of the

2 The term "first straight line" does not necessarily imply that a second straight line is following. It means only that this is the first part of the curve that appears as a straight line, and the rate of the corresponding process can be described as a first-order reaction. Possibly, the rate given by the first straight line represents the sum of several turnover rates.

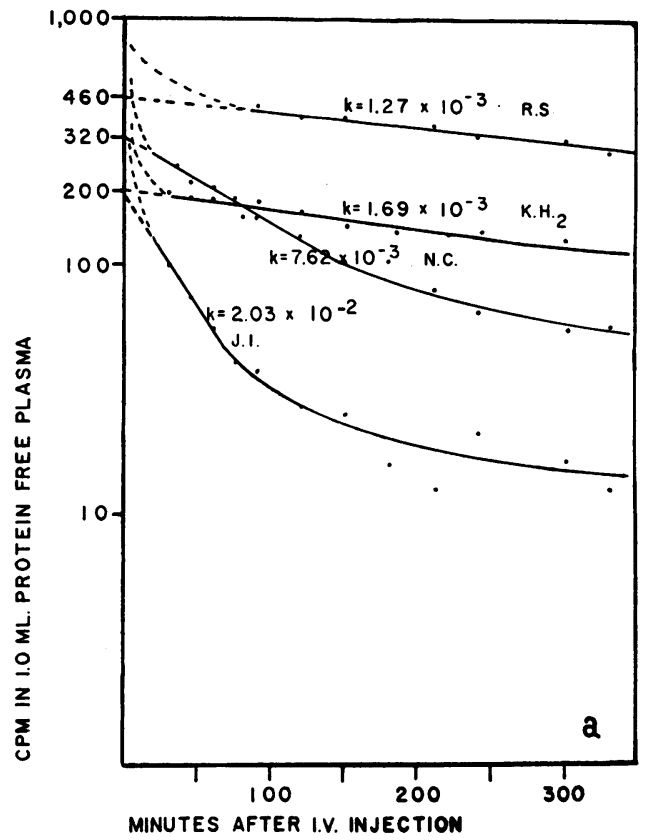

Fig. 1. a) Time course of the disappearance of FREE L-PHENYLALANINE-C ${ }^{14}$ FROM DEPROTEINIZED PLASMA in Patients J.I., N.C., K.H.z, And R.S. All values are corrected for a single interavenous injection of $7.6 \times 10^{6}$ cpm. The experimental values of the dotted curved lines are not shown in the diagram. The straight lines were drawn by inspection of the points. Only in less clear situations was the method of least squares applied; $k=$ first-order reaction rate constant of the first straight line in minutes $^{-1}$.

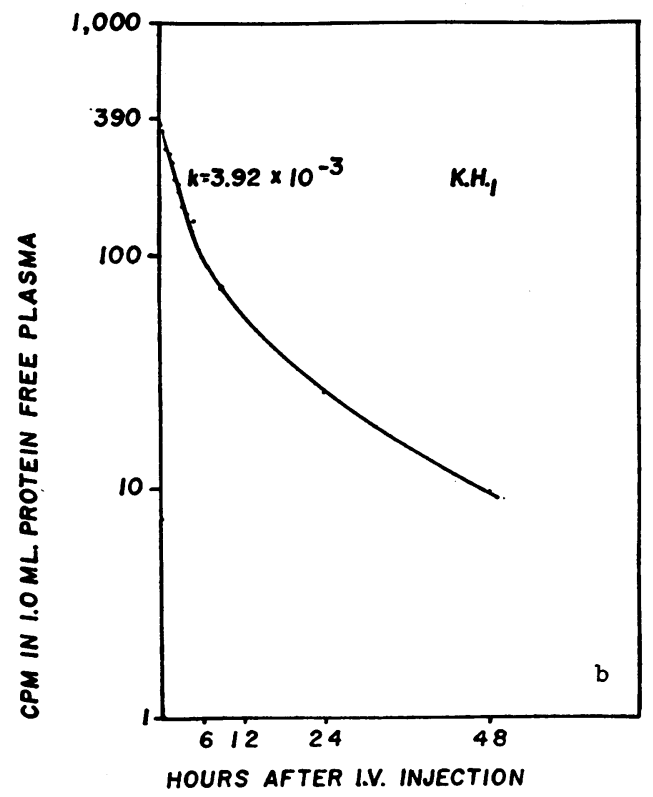

b) As above, but in Patient K.H. ${ }_{1} 1.115 \times 10^{7} \mathrm{cpm}$ was injected; $k$ is again given in minutes ${ }^{-1}$. 
plasma disappearance curve. Therefore, the extrapolation of the first straight line, which carries with it the implication that turnover is constant throughout the earlier part of the curve, must introduce some error in the phenylalanine space. This criticism is true of all slope-intercept methods, but is serious only when turnover is rapid compared with the time required for mixing in the pool. We have calculated that the error does not exceed about 15 per cent for J.I. and 6 per cent for N.C. The estimation of the free phenylalanine pool in the intravascular plasma compartment is easy if the plasma volume is determined as Evans blue space. From there the flux in or out of the plasma compartment by turnover may be calculated from the equation:

$$
\text { flux }_{\text {plasma }}=V_{\text {plasma }} \times c_{\text {plasma }} \times k
$$

where $c_{\text {plasma }}$ is the concentration of free phenylalanine in milligrams per milliliter plasma and $k$ the slope constant of the first straight line $(k=$ $\left.1 / t_{t}=0.693 / t_{\frac{1}{2}}\right)$. All values are considered to be in fairly good agreement for this kind of experiment from one patient to the other-that is, \pm 30 per cent from the average and given in $\mathrm{Ta}$ - ble I as milligrams free phenylalanine leaving the intravascular compartment per minute or returning to it. Strictly speaking, influx and efflux of the intravascular compartment are not equal, since the system under consideration is leaking; that is, some free phenylalanine is lost with the urine. However, for the first 6 hours the radioactivity excreted amounts to only 2 to 5 per cent of the total dose injected. A substantial part of it might have been excreted during the early phase of equilibration at a time when the specific activity of the free phenylalanine in plasma was relatively high. Since we did not want to catheterize our patients, no early urine specimens were obtained for verification of this assumption.

Maurer (17) likewise found no evidence for significant intracellular concentration of $\mathrm{S}^{35}$-methionine in humans or rabbits, but the situation with respect to other amino acids might be quite different (27). Noall, and Christensen and their co-workers have shown that the nonmetabolizable amino acid, $\alpha$-aminoisobutyric acid is many-fold concentrated in human muscle (28) and in various rat tissues (29). In experiments similar to those described above in which $\alpha$-aminoisobutyric acid

TABLE I

Summary of values obtained in the patients

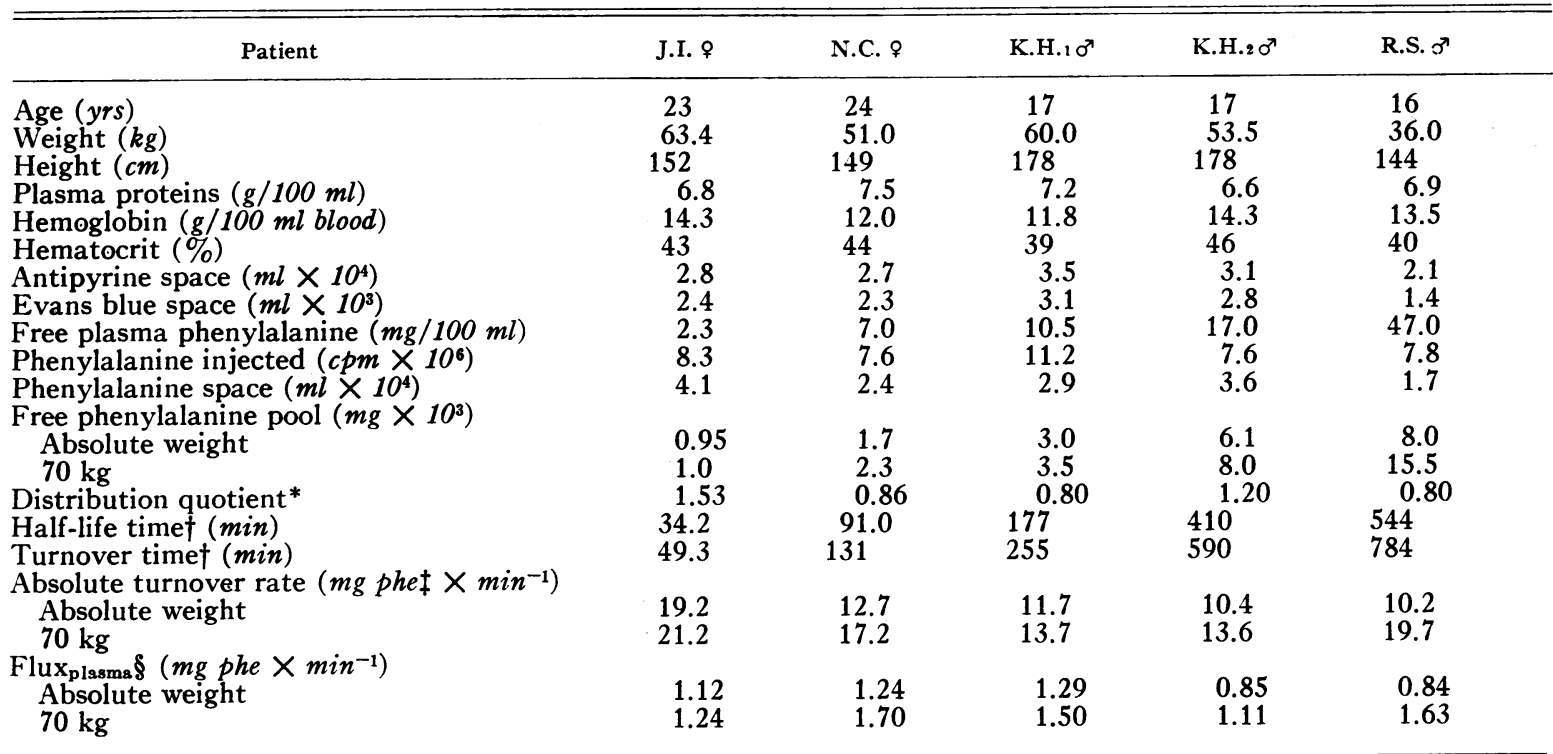

* The distribution quotient of free phenylalanine in plasma to the average free phenylalanine concentration in tissue as derived from the equation by Dost (24).

t Values calculated from the first straight line.

$\neq$ phe $=$ Free phenylalanine.

$\S$ Free phenylalanine leaving or entering the intravascular plasma compartment by turnover. 
was used instead of phenylalanine, evidence for an (average) extravascular concentration of at least two times that of plasma was obtained by us in one control and in two phenylketonuric patients. Under the assumption that the concentration of $\alpha$-aminoisobutyric acid in the total extracellular space is the same as in the intravascular fluid, the concentration of $\alpha$-aminoisobutyric acid within the cell is even higher.

To obtain further information on the rapidity of equilibration processes, we have also studied the time required for labeled phenylalanine to be equilibrated in vivo between plasma and red cells in Patient K.H. when his plasma phenylalanine level was $10.5 \mathrm{mg}$ per $100 \mathrm{ml}$. The distribution quotient between red cells and plasma was constant throughout the entire experiment-that is, between 5 and 300 minutes. Since equilibration between plasma and red cells was already complete before 5 minutes after the injection had elapsed, it might not seem unreasonable to assume that all equilibration processes of the labeled phenylalanine in J.I., N.C., and K.H. have essentially come to an end at about 25 minutes, when the first straight line starts. That the uptake of phenylalanine for protein synthesis is also fast will be demonstrated in a second paper (21). Thus, it will be shown that the appearance of a significant amount of labeled plasma proteins in the intravascular compartment can be demonstrated about 30 minutes after the injection of labeled phenylalanine. However, it cannot be excluded that some equilibration is still going on after the first straight line has begun.

If our basic assumption is correct-that equilibration is complete or nearly complete when the first straight line starts and a steady state exists in our patients-then the third component can be best explained by a new process that is showing up. The third component starts in J.I., N.C., and $\mathrm{K} . \mathrm{H}_{._{1}}$ at an interval after zero time that is of the order of one turnover time or a little more. After this time, about two-thirds of the old molecules have left the free phenylalanine pool, or only about one-third of the old molecules remain. The return of a small fraction of labeled free phenylalanine from proteins or protein precursor pool to the free phenylalanine pool is, therefore, sufficient to cause significant deviation of the first straight line from its first-order rate. It could also be argued that the appearance of the third component coincides with the end of mixing with slowly equilibrating compartments, which are overburdened with an excessive load of free phenylalanine. It is noteworthy in this regard that the Evans blue space is in a constant relationship with the calculated phenylalanine space-namely, 6 to 11 per cent of it - and that no correlation between plasma phenylalanine levels and phenylalanine space was observed. If some compartments become rate-limiting in the uptake or exchange of free phenylalanine, then it is likely that with increasing plasma phenylalanine concentrations the size of the phenylalanine space decreases, or the time of the intervals between injection of the labeled phenylalanine and the appearance of the first straight line increases, or both. Only the timeinterval increase was valid in Patient R.S., with a plasma phenylalanine concentration of $47 \mathrm{mg}$ per $100 \mathrm{ml}$, while in all the other patients having plasma phenylalanine levels of $2.3,7.0,10.5$, and $17.0 \mathrm{mg}$ per $100 \mathrm{ml}$, the time of appearance of the first straight line was essentially the same.

If our basic supposition is false, that equilibration has essentially come to an end when the first straight line starts, then we have to assume that mixing processes are still going on until the third component appears. If the latter view is correct, we have to assume the existence of a dynamically more active and a dynamically less active body compartment, of which our first straight line seems to reflect the first metabolic glycine pool described by Arnstein and Neuberger (30) as well as by Watts and Crawhall (31). The first straight line, then, represents mainly the active body compartment deriving from the fact that dynamically more active organs, such as kidney and liver, have a predominant blood supply and, more likely therefore, a faster equilibration. This is supported by the appearance of a significant amount of labeled protein in the plasma at an early stage. The third component of the disappearance curve would have to reflect complete equilibration between the dynamically more active and the dynamically less active compartment. If this is so, the distribution volume of the dynamically more active and less active compartments would have a larger free phenylalanine distribution volume than has the corresponding water space, indicating significant intracellular enrichment. Calculations from the 
final slope of the third component could be used only for estimation of relative turnover rates, since the total phenylalanine pool would be too large, due to processes going on during the time of the first straight line. If this enlarged space were not taken into consideration, the calculated absolute turnover rates would be tremendously high; i.e., 5 and 9 times higher in J.I. and K.H., respectively, than those calculated from the first straight line. In addition, the final slopes possibly do not represent ultimate turnover rates only but also return of labeled material from the proteins or precursor pool, respectively. However, with the data at hand, we feel that the first hypothesis of complete, or nearly complete, equilibration when the first straight line starts is the better model.

All calculations are derived from the first straight line and the values so obtained are summarized in Table I. If our first model is correct, the first straight line represents true turnover as defined above. If the second model should prove correct, the first straight line gives only upper limits for metabolic turnover going on in the dynamically more active body compartment on account of additional unfinished equilibration processes. The plotted curves do not permit a sound resolution into more components owing to the fact that the final slopes are subject to considerable experimental error and, as in Patient N.C., were not observed over a longer period of time.

Our data indicate that phenylalanine concentrations as found in the plasma of phenylketonuric

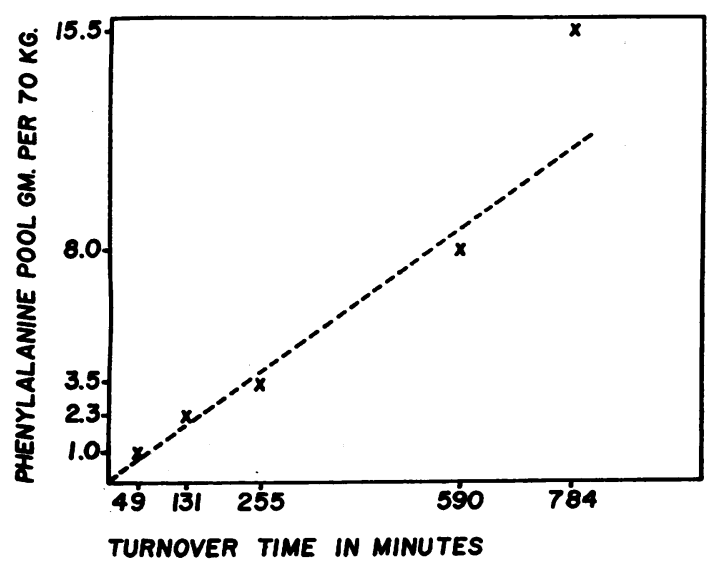

Fig. 2. Correlation of magnitude and turnover time OF THE FREE PHENYLALANINE POOLS.

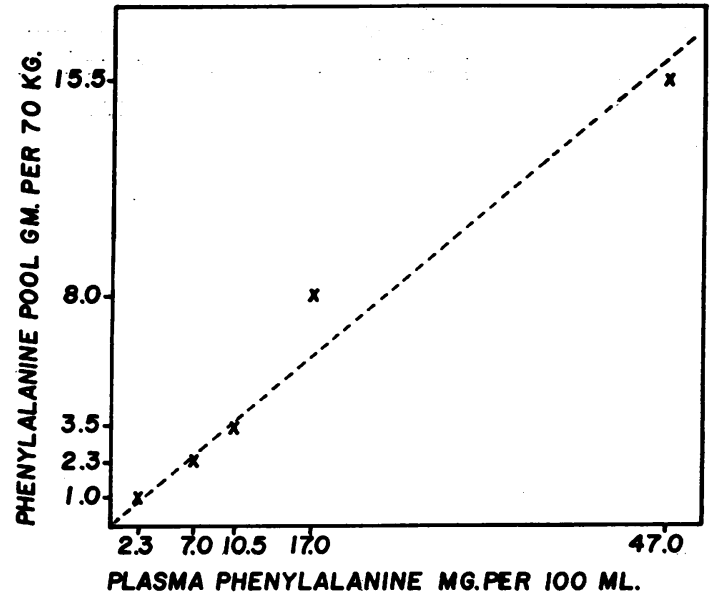

Fig. 3. Correlation of Magnitude of FREe PHenylALANINE POOLS AND PLASMA PHENYLALANINE CONCENTRATIONS.

individuals are applicable for inhibition studies in tissue, since the concentration of this amino acid appears to be of the same order of magnitude in plasma and tissue. This discrepancy in Bickis and co-workers' (12) in vitro and our in vivo experiments, as mentioned earlier, however, could not be resolved on this basis. Perhaps the rate of conversion from tyrosine to $p$-hydroxyphenylpyruvic acid was diminished in the in vitro studies, or tissue homogenates and slices per se react differently to phenylalanine.

The slopes of the first straight line correlate with the magnitude of the plasma phenylalanine levels; the higher these levels, the smaller the values for the slope constant, and since the slopes of those curves express the turnover time of the free phenylalanine pool, there must be a positive correlation between turnover times and phenylalanine pools. This correlation is illustrated by Figure 2, and the dependence of the correlation between plasma phenylalanine level and free phenylalanine pool is illustrated in Figure 3.

\section{SUM MARY}

Four patients suffering from phenylpyruvic oligophrenia were subjected to studies of distribution, pool size, and turnover rate of free phenylalanine. Our data were obtained from the disappearance curves of intravenously injected Lphenylalanine- $\mathrm{C}^{14}$. The experiments indicate no substantial intracellular concentration, as derived 
by comparing the phenylalanine space to antipyrine space. A positive correlation existed between the free phenylalanine pool and its turnover time and of phenylalanine pool to plasma phenylalanine concentration. The free phenylalanine pool for normal individuals was estimated to be of the order of $1 \mathrm{~g}$ per $70 \mathrm{~kg}$ body weight.

\section{ACKNOWLEDGMENT}

We are indebted to Dr. E. H. Frieden for his helpful discussion of this paper, and to Mrs. M. J. Spiller and Miss C. Howes, whose careful supervision of the patients, to whom credit also is due, made this project possible.

\section{REFERENCES}

1. Udenfriend, S., and Cooper, J. R. The enzymatic conversion of phenylalanine to tyrosine. J. biol. Chem. 1952, 194, 503.

2. Mitoma, C. Studies on partially purified phenylalanine hydroxylase. Arch. Biochem. 1956, 60, 476.

3. Wallace, H. W., Moldave, K., and Meister, A. Studies on conversion of phenylalanine to tyrosine in phenylpyruvic oligophrenia. Proc. Soc. exp. Biol. (N. Y.) 1957, 94, 632.

4. Mitoma, C., Auld, R. M., and Udenfriend, S. On the nature of enzymatic defect in phenylpyruvic oligophrenia. Proc. Soc. exp. Biol. (N.Y.) 1957, 94, 634.

5. Kaufman, S. Studies on the mechanism of the enzymatic conversion of phenylalanine to tyrosine. J. biol. Chem. 1959, 234, 2677.

6. Miyamoto, M., and Fitzpatrick, T. B. Competitive inhibition of mammalian tyrosinase by phenylalanine and its relationship to hair pigmentation in phenylketonuria. Nature (Lond.) 1957, 179, 199.

7. Pare, C. M. B., Sandler, M., and Stacey, R. S. Decreased 5-hydroxytryptophan decarboxylase activity in phenylketonuria. Lancet 1958, 2, 1099.

8. Baldridge, R. C., Borofsky, L., Baird, H., III., Reichle, F., and Bullock, D. Relationship of serum phenylalanine levels and ability of phenylketonurics to hydroxylate tryptophan. Proc. Soc. exp. Biol. (N. Y.) $1959,100,529$.

9. Hanson, A. Inhibition of brain glutamic acid decarboxylase by phenylalanine metabolites. Wiss. Natur. 1958, 45, 423.

10. Bickel, H., Gerrard, I., and Hickmans, E. M. The influence of phenylalanine intake on the chemistry and behaviour of a phenylketonuric child. Acta pediat. (Uppsala) 1954, 43, 64.

11. Hsia, D. Y., Knox, W. E., Quinn, K. V., and Paine, R. S. A one-year, controlled study of the effect of low-phenylalanine diet on phenylketonuria. Pediatrics 1958, 21, 178.
12. Bickis, I. J., Kennedy, J. P., and Quastel, J. H. Phenylalanine inhibition of tyrosine metabolism in the liver. Nature (Lond.) 1957, 179, 1124.

13. Grümer, H.-D., and Woodard, C. Tolerance tests with $p$-hydroxyphenylpyruvic acid in phenylketonuric subjects. I. in Proc. Internat. Medical Conference on Mental Retardation. New York, Grune \& Stratton, 1960, p. 313.

14. $\mathrm{Wu}, \mathrm{H}$., and Sendroy, J., Jr. Pattern of $\mathrm{N}^{15}$-excretion in man following administration of $\mathrm{N}^{15}$-labeled L-phenylalanine. J. appl. Physiol. 1959, 14, 6.

15. Wu, H., Sendroy, J., Jr., and Bishop, C. W. Interpretation of urinary $\mathrm{N}^{15}$-excretion data following administration of an $\mathrm{N}^{15}$-labeled amino acid. $\mathrm{J}$. appl. Physiol. 1959, 14, 11.

16. Tschudy, D. P., Bacchus, H., Weissman, S., Watkin, D. M., Eubanks, M., and White, J. Studies on the effect of dietary protein and caloric levels on the kinetics of nitrogen metabolism using $\mathrm{N}^{15} \mathrm{~L}$ aspartic acid. J. clin. Invest. 1959, 38, 892.

17. Maurer, W. Die Grösse des Umsatzes von Organund Plasmaeiweiss, in Dynamik des Eiweisses, 10. Colloquium der Gesellschaft für Physiologische Chemie, 1959, in Mosbach. Berlin, Springer Verlag, 1960, p. 1.

18. Gutman, A. B., Yü, T. F., Black, H., Yalow, R. S., and Berson, S. A. Incorporation of glycine-1- $\mathrm{C}^{\mathbf{1 4}}$, glycine-2- $\mathrm{C}^{14}$, and glycine- $\mathrm{N}^{15}$ into uric acid in normal and gouty subjects. Amer. J. Med. 1958, 25, 917.

19. Sprinson, D. B., and Rittenberg, D. The rate of interaction of the amino acids of the diet with the tissue proteins. J. biol. Chem. 1949, 180, 715.

20. San Pietro, A., and Rittenberg, D. A study of the rate of protein synthesis in humans. II. Measurement of the metabolic pool and the rate of protein synthesis. J. biol. Chem. 1953, 201, 457.

21. Grümer, H.-D., Koblet, H., and Woodard, C. Phenylalanine metabolism in the phenylpyruvic condition. II. An attempt to calculate the daily incorporation of phenylalanine into proteins. Submitted for publication.

22. Jervis, G. A. Phenylpyruvic oligophrenia (phenylketonuria). Ass. Res. nerv. Dis. Proc. 1954, 33, 259.

23. Brodie, B. B., Axelrod, J., Soberman, R., and Levy, B. B. The estimation of antipyrine in biological materials. J. biol. Chem. 1949, 179, 25.

24. Dost, F. H. Der Blutspiegel. Kinetik der Konzentrationsabläufe in der Kreislaufflüssigkeit. Leipzig, Georg Thieme Verlag, 1953, p. 129.

25. La Du, B. N., and Michael, P. J. An enzymatic spectrophotometric method for the determination of phenylalanine in blood. J. Lab. clin. Med. 1960, 55, 491.

26. Kingsley, G. R. The direct biuret method for the determination of serum proteins as applied to 
photoelectric and visual colorimetry. J. Lab. clin. Med. 1942, 27, 840.

27. Appel, K. R., Appel, E., and Maurer, W. Konzentration und Austauschrate des freien Methionins im Gehirn der Ratte. Biochem. Z. 1960, 332, 293.

28. Noall, M. W., Riggs, T. R., Walker, L. M., and Christensen, H. N. Endocrine control of amino acid transfer; distribution of an unmetabolizable amino acid. Science 1957, 126, 1002.
29. Christensen, H. N., Thompson, D. H., Markel, S., and Sidky, M. Decreasing "amino acid hunger" of human muscle with age. Proc. Soc. exp. Biol. (N. Y.) 1958, 99, 780.

30. Arnstein, H. R. V., and Neuberger, A. Hippuric acid synthesis in the rat. Biochem. J. 1951, 50, 154.

31. Watts, R. W. E., and Crawhall, J. C. First glycine metabolic pool in man. Biochem. J. 1959, 73, 277. 